\title{
An invasive infection caused by the thermophilic mold Talaromyces thermophilus
}

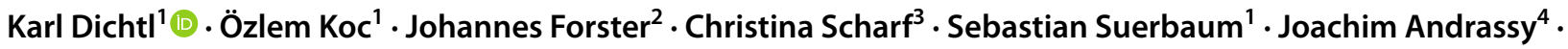 \\ Johannes Wagener ${ }^{2,5,6} \cdot$ Ines Schroeder ${ }^{3}$
}

Received: 16 April 2021 / Accepted: 22 June 2021 / Published online: 30 June 2021

(c) The Author(s) 2021

\begin{abstract}
Background Increasing incidence of invasive infections caused by rare fungi was observed over the recent years.

Case Here, we describe the first reported case of an infection caused by the thermophilic mold Talaromyces thermophilus. Cultivation and, hence, identification of this fastidious organism is challenging since standard incubation conditions are not sufficient. Retrospective analysis of patient samples and in vitro experiments demonstrated that testing for fungal antigens, i.e., the cell wall components galactomannan and $\beta-1,3-\mathrm{D}$-glucan, is a promising tool.
\end{abstract}

Keywords Talaromyces $\cdot$ Invasive fungal infection · Thermophile $\cdot$ Antigen testing $\cdot$ Serology

\section{Introduction}

Invasive mold infections (IMI) are a major threat for immunosuppressed patients with mortality rates of up to $95 \%$ $[1,2]$. Particularly, individuals undergoing myeloablative chemotherapy and hematopoietic stem cell transplantation (HSCT) are considered a high-risk population [1]. However, the incidence in non-canonical risk patients was also found to be rising over the recent years, e.g., in individuals in need of intensive care treatment, with a history of solid organ

Karl Dichtl

dicht1@mvp.lmu.de

1 Max von Pettenkofer-Institut für Hygiene und Medizinische Mikrobiologie, Medizinische Fakultät, LMU München, Munich, Germany

2 Institut für Hygiene und Mikrobiologie, Julius-Maximilians-Universität Würzburg, Würzburg, Germany

3 Department of Anesthesiology, LMU Hospital, Munich, Germany

4 Department of General, Visceral, and Transplant Surgery, LMU Hospital, Munich, Germany

5 Department of Clinical Microbiology, School of Medicine, Trinity College Dublin, The University of Dublin, St James's Hospital Campus, Dublin, Ireland

6 Nationales Referenzzentrum für Invasive Pilzinfektionen (NRZMyk), Jena, Germany transplantation, influenza, or less severe regimens of immunosuppression [1].

Notably, this diversification of risk factors comes along with a diversification of the pathogen spectrum: Besides the most common cause of IMI, i.e., members of the genus Aspergillus, a broad range of other well-known but also emerging molds was more and more frequently identified in invasive fungal disease [3-7]. While the diagnostic assays to detect invasive aspergillosis (IA) have been refined over the past decades, we still lack appropriate tools to meet the challenge of diagnosing these new pathogens [3-5, 7-9]. To date, specific serologic assays for non-Aspergillus-IMI are not commercially available [8]. Molecular methods for analysis of clinical specimens still suffer from a lack of standardization and are either not recommended by current guidelines or only with restrictions [3-5]. The prospects of success of cultivation highly depend on the nature of the fungus: the need for special handling in the preanalytical phase and specific growth conditions, e.g., prolonged incubation, complicate the diagnosis of IMI $[4,5,7]$. Particularly incubation at $37{ }^{\circ} \mathrm{C}$, which is the standard condition in medical microbiology, is a major contributor to false-negative cultures since this temperature is too high to sustain growth of many molds [5, 7]. Contrarily, there are exceptional cases of infections due to thermophilic organisms that require high incubation temperatures.

To the best of our knowledge, we present the first case of an infection caused by the thermophilic mold Talaromyces 
thermophilus. We outline not only possibilities but also limitations for diagnosing this rare pathogen. Additional analyses and in vitro experiments elucidate the potential and pitfalls of antigen testing for this exceptional IMI.

\section{Case}

At the age of 25 years, a male Caucasian was diagnosed with an angiomyxoma located in the head of the pancreas and the hepatic hilum. Due to the constantly growing tumor, several complications and life-threatening events occurred, e.g., portal vein occlusion, ascites, and several episodes of upper gastrointestinal bleeding. Since all conservative therapy approaches were exhausted after four years of therapy, the patient consented to a radical tumor resection and multivisceral transplantation including liver, pancreas, stomach, small intestines, and colon ascendens (day 0). The patient received a calcineurin inhibitor-based immunosuppression combined with prednisolone and mycophenolate. However, the postoperative course was complicated by numerous drawbacks like primary transplant failure of the liver and pancreas, thrombophilia with thrombosis of the inferior vena cava and the portal vein, anastomotic leakage, and multiple septic episodes. As a result, the patient underwent several procedures and operations. Pancreatectomy, colectomy, total gastrectomy, and distal esophagectomy were performed on day 53 with the aim to regain infection control. On day 61 , the patient received a second liver transplant, which again failed to provide sufficient function in the further course.

From day 67 on, several serum samples were tested positive for Aspergillus antigen galactomannan (GM; cut-off index: 0.50 ). At this point, the patient was already receiving caspofungin for three weeks because of continuous intestinal leakage and a previous finding of Candida spp. in the stool. Furthermore, Candida albicans had been recovered from a superficial swab of the abdominal wound (day 37). Upon the report of GM antigenemia, Aspergillus-specific treatment with liposomal amphotericin B (3 mg / kg once daily) was added to the therapeutic regime (day 68 ).

However, the patient, who was intubated and ventilated, did not have signs of respiratory tract infection, and bronchoalveolar lavage did not yield growth of Aspergillus spp. and was tested negative for GM (cut-off index: 0.50). Since antigenemia remained the only sign of IA, we tried to identify a cause for GM false-positivity. The day before the first positive serology, the digestion enzyme mix Nortase ${ }^{\circledR}$ (Repha, Langenhagen, Germany) was administered via a feeding tube to compensate the patient's pancreatic insufficiency (day 66). The encapsulated powder contains fungal enzymes synthesized by Rhizopus oryzae and by Aspergillus oryzae. Therefore, powder diluted in $20 \mathrm{~mL}$ of water was tested and yielded a strongly positive reaction in the GM
ELISA (Platelia Aspergillus GM ELISA, Bio-Rad Laboratories, Hercules, CA, USA). Upon this result, amphotericin $B$ was discontinued, as antigenemia was considered to be a result of Nortase ${ }^{\circledR}$ administration [10].

An unexpected turn of events occurred, when two intraabdominal samples again proved the initial suspicion of IMI: On day 71, peritoneal fluid was found to contain 260 neutrophils/ $\mu$ l and to be strongly reactive (index: 4.86 ) in the GM ELISA, which was accompanied by a peak neutrophil leukocyte count of $30 \mathrm{G} / \mathrm{L}$. Over the following days, leukocytes dramatically dropped to $0.9 \mathrm{G} / \mathrm{L}$. After nine days of incubation (day 74), a mold was recovered from a swab of a suspicious alteration of the abdominal mesh, which had been inserted on day 47, during jejunostomy for a biliodigestive anastomosis. This mold was identified as Talaromyces thermophilus (synonyms: T. dupontii or Thermomyces dupontii; anamorph: Penicillium dupontii) via MALDI-TOF (Bruker Corporation, Billerica, MA, USA) and genetic analysis, i.e., sequence analysis of a PCR amplicon (using the ITS4 and ITS5 primers) of a ribosomal DNA locus (rDNA). A second swab, which was obtained from an abdominal drain as part of the routine screening on day 78, also yielded growth of this fungus, thereby disproving the hypothesis of an environmental contaminant.

Despite anti-infective therapy, several surgical and endoscopic interventions, and maximum escalation of intensive care treatment, the patient's condition deteriorated. Regarding the poor prognosis, the therapy was changed for a palliative approach in consultation with the patient's family, and the patient deceased on day 79 . The relatives refused an autopsy.

Since the cause of antigenemia remained unclear, additional analyses were performed afterwards. GM positivity of Nortase ${ }^{\circledR}$ was confirmed by analysis of capsules of different batches. In addition, testing for the fungal cell wall polysaccharide $\beta$-1,3-D-glucan (BDG; Fujifilm Wako Chemicals Europe, Neuss, Germany) detected high amounts of BDG (up to $0.2 \mu \mathrm{g}$ per capsule). The peritoneal fluid and all analyzed sera were BDG positive (Fig. 1). Notably, BDG antigenemia occurred already more than a week before Nortase $®$ administration (Fig. 1).

To address the question, whether the GM ELISA or the BDG assay is capable of detecting T. thermophilus infection, in vitro antigen production of the isolated strain was assessed. Briefly, $5^{*} 10^{\wedge} 6$ conidia / $\mathrm{mL}$ of $T$. thermophilus and of an Aspergillus fumigatus control (patient isolate D141) were incubated in $10 \mathrm{~mL}$ fetal bovine serum for $72 \mathrm{~h}$ at $37^{\circ} \mathrm{C}$. The culture supernatants were centrifuged, sterile filtered and subsequently tested for BDG and GM analogously to serum samples. If necessary, supernatants were diluted in medium in order to allow quantification of the results. In comparison to the medium control, T. thermophilus supernatants yielded a 42 -fold reactivity in the GM 


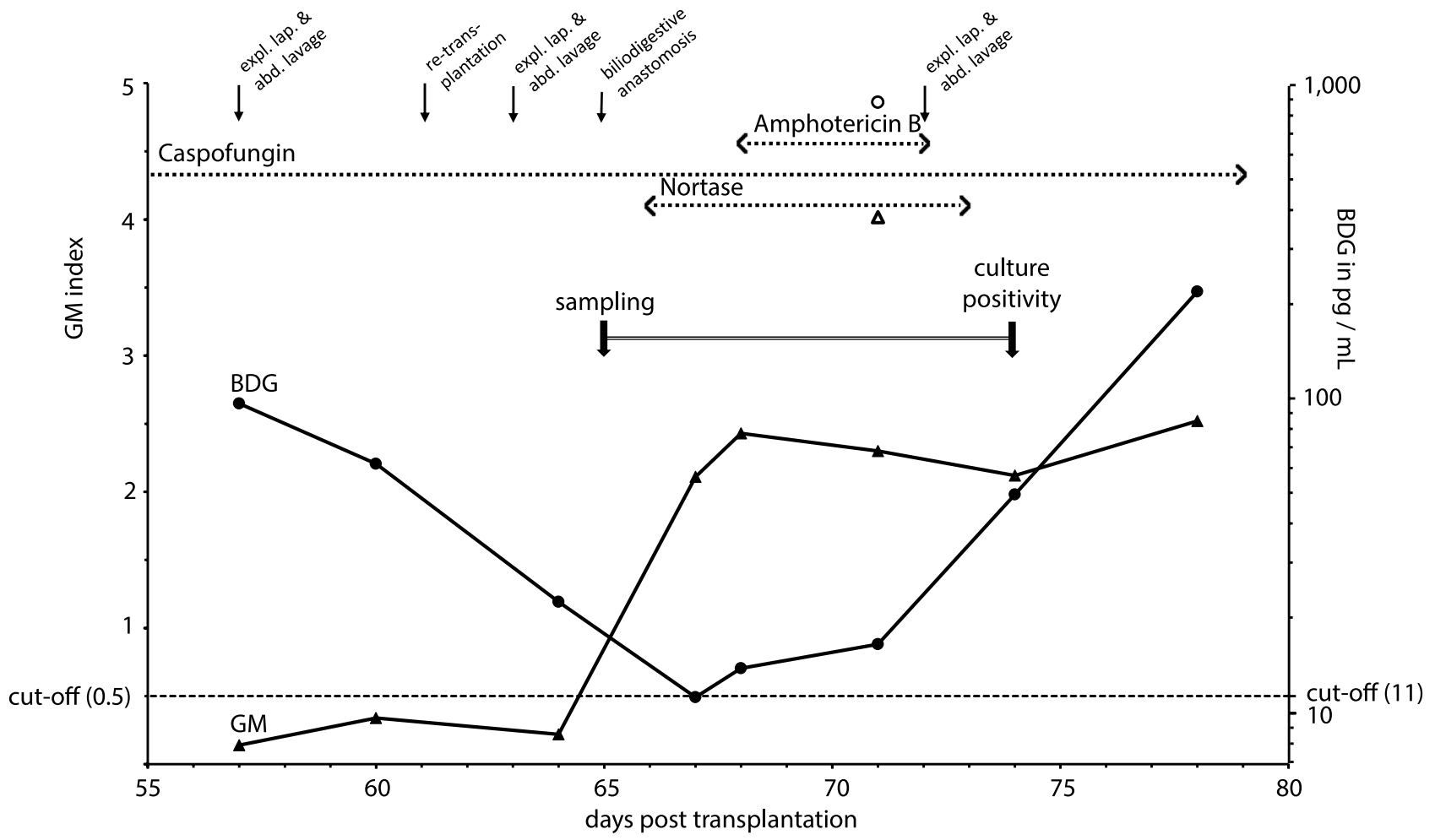

Fig. 1 Time course of serology, antifungal therapy, and abdominal surgical procedures. Results of GM (full triangles, primary y-axis) and BDG (full circles, secondary $y$-axis) antigen testing from serum were plotted according to the time course of infection ( $\mathrm{x}$-axis: days post transplantation). Empty triangle and circle represent the respective test result of peritoneal fluid. Y-axes were scaled to allow to dis-

ELISA and a 15-fold higher concentration of BDG (Fig. 2a, b). As expected, results in both assays were by far higher measuring the Aspergillus supernatants (514-fold for GM and 544-fold). It is highly likely that much of this significant difference can be attributed to the massively impaired and delayed growth of $T$. thermophilus at $37{ }^{\circ} \mathrm{C}$ (Fig. 2c: 500 conidia of the respective strains were inoculated on Sabouraud medium [Sabouraud G + C, Becton Dickinson, Franklin Lakes, NJ, USA]). Notably, the thermophilic fungus failed to grow at $30{ }^{\circ} \mathrm{C}$ at all (data not shown).

Antifungal susceptibility testing of $T$. thermophilus was performed according to EUCAST recommendations for Aspergillus spp. with minor modifications taking into account the specific characteristics of the thermophilic organism $\left(45^{\circ} \mathrm{C}\right.$ for $48 \mathrm{~h}$; Sensititre YeastOne YO10 assay [TREK Diagnostic Systems, Cleveland, OH, USA]) [11]. The minimal inhibitory / effective concentrations (MIC / MEC) are listed in Table 1. Applying the A. fumigatus cutoffs, the T. thermophilus isolate was susceptible to amphotericin $\mathrm{B}$, posaconazole, and voriconazole. The echinocandin MECs, for which no Aspergillus epidemiological cut-offs play a single cut-off line for both assays (dashed line). Dotted lines and the doubled line indicate the duration of drug administration and the time to positivity of $T$. thermophilus cultivation, respectively. expl. lap. \& abd. lavage, exploratory laparotomy and abdominal lavage

(ECOFFs) are available, were low and suggestive of susceptibility $(0.015 \mu \mathrm{g} / \mathrm{mL})$.

\section{Discussion}

Over the last decades, the incidence of IMI has risen, which can primarily be attributed to advances in immunosuppressive therapies and, thus, a growing risk population $[1,3-5$, 7]. Notably, an emergence of infections with rare filamentous fungi was observed over the recent years [2-7, 12-15]. Due to climate change and global warming, appearance of new fungal pathogens or spread of endemic mycoses to new areas is expected [16, 17]. An infamous example for an (so far) endemic pathogen is the mold still known today as Penicillium marneffei, which is a common cause of severe and often fatal infections in AIDS patients in Southeast Asia $[18,19]$. Notably, P. marneffe $i$ was reclassified in the genus Talaromyces in 2011 (T. marneffei) [20]. To date, virtually all infections caused by Talaromyces can be attributed to this single species, and, consequently, the term "talaromycosis" 
Fig. 2 Comparison of in vitro antigen production and growth of A. fumigatus and T. thermophilus. Culture supernatants of A. fumigatus (strain D141) and the isolated T. thermophilus strain were analyzed for GM (a) and BDG (b). 500 conidia of the respective strains were inoculated on Sabouraud medium and incubated under the indicated conditions (c)

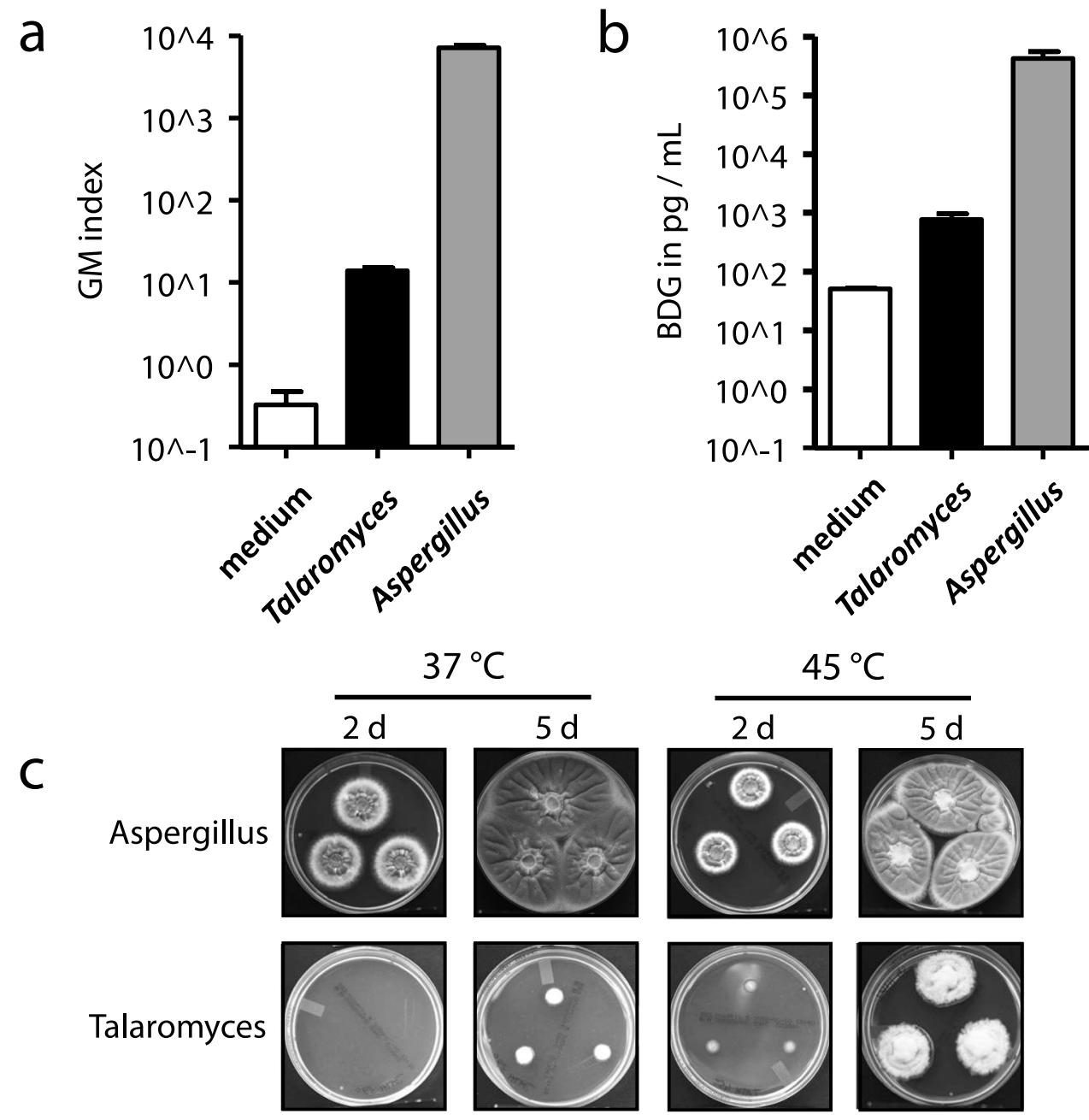

Table 1 Results of antisusceptibility testing

\begin{tabular}{lll}
\hline Antifungal agent & MIC $(\mathrm{mg} / \mathrm{l})$ & Interpretation \\
\hline Fluconazole & $>256,000$ & $\mathrm{R}$ \\
Posaconazole & 0.030 & $\mathrm{~S}$ \\
Voriconazole & 0.015 & $\mathrm{~S}$ \\
Amphotericin B & 0.250 & $\mathrm{~S}$ \\
& MEC & \\
Anidulafungin & 0.015 & - \\
Caspofungin & 0.015 & - \\
Micafungin & 0.015 & - \\
\hline
\end{tabular}

$M I C$ minimal inhibitory concentration, $M E C$ minimal effective concentration

is used exclusively for fungal disease due to T. marneffei $[18,19]$.

We report to our knowledge the first case of an infection due to another member of the genus Talaromyces: the thermophilic organism T. thermophilus. It is a certain limitation of this case that no histopathology of the infected body site was available, which would represent the adequate diagnostic to exclude contamination with airborne spores or fungal cells originating from the gut. Due to the long incubation time after sampling, the finding of a mold was only available at a time point, when further invasive diagnostic procedures were dispensed with respect to the family's consideration to change the therapy for a palliative treatment. However, the depicted case of a postoperative wound infection and peritonitis still meets the criteria of proven infection according to the EORTC/MSG consensus definitions of invasive fungal disease [21].

For the longest time, T. thermophilus has been regarded as an environmental saprophyte, which degrades organic materials in warm and humid environments, e.g., piles of agricultural and forestry products, tolerating temperatures of $50-60{ }^{\circ} \mathrm{C}$ [22]. Scientific interest in this mold has been limited to the biotechnological setting because of its thermostable enzymes [22, 23]. The definitive taxonomic status of $T$. thermophilus is still subject of outstanding investigations [24]. Based on phenotypic and genetic findings, a reclassification from the genus Talaromyces to the genus 
Thermomyces, which does not comprise any human pathogenic species at all, was proposed.

A major cause, if not the main cause, of the low pathogenicity of Thermomyces spp. is their inability to grow at $37^{\circ} \mathrm{C}$, since these organisms prefer higher temperatures. It is generally accepted to apply the term thermophilic, if organisms tolerate high temperatures or if high temperatures even provide the optimal growth condition. However, the exact limits defining "thermophile" are controversial and remain to be determined. Infections with thermophilic fungi are extremely rare with only few anecdotal reports published, e.g., mycoses due to Thermoascus crustaceus and Myceliophthora thermophila [25-30]. However, these fungi are cultivated reliably under standard laboratory conditions (30-37 ${ }^{\circ} \mathrm{C}$ ). In contrast, in vitro growth of $T$. thermophilus is impeded at $30^{\circ} \mathrm{C}$ and significantly impaired and delayed at $37^{\circ} \mathrm{C}$ (data not shown and Fig. 2c), which makes mycological diagnostics challenging. It therefore seems conceivable that mycoses caused by thermophiles could be underreported due to these limitations. Furthermore, even upon isolation, the finding of $T$. thermophilus might be misinterpreted as contamination.

In contrast to culture, testing for fungal antigens might be a valuable diagnostic tool. The initial suspicion of IMI was based on a positive GM serology. The GM ELISA is an Aspergillus-specific test known for its high specificity and almost negligible cross reactivity to other fungal pathogens [31]. However, the close phylogenetic relationship of the genera Talaromyces and Aspergillus might be an explanation for this finding [24]. Testing for GM in culture supernatants demonstrated that $T$. thermophilus is capable of producing GM (or at least cross-reactive antigens) in vitro (Fig. 2a). The massively impaired growth at $37{ }^{\circ} \mathrm{C}$ could explain the lower amount of GM and BDG detected in the supernatant of the T. thermophilus isolate. Retrospective analysis of the panfungal antigen BDG in the patient's sera yielded positive results throughout the entire course of infection and, notably, occurred ten days before GM seropositivity: from the time point of BDG antigenemia, three additional sera had to be sampled until the GM ELISA turned positive (Fig. 1). The finding of a temporal advantage of BDG over GM has been repeatedly observed [32, 33]. However, BDG testing does not allow a discrimination between a range of different fungal infections. Our patient had a history of intestinal colonization with Candida; therefore, it cannot be excluded that, as a result of mucosal leakage, he suffered from a parallel intra-abdominal Candida infection causing BDG antigenemia. BDG and GM were also detected in peritoneal fluid (Fig. 1). Anecdotal reports and small case series previously suggested that this analysis might be helpful in the setting of intra-abdominal fungal infections [34-36].

Interpretation of serological results was further complicated by the finding that the patient received at least one drug contaminated with both fungal antigens (Fig. 1): due to the pancreatectomy, digestion enzymes had to be substituted. The administered capsulated drug, i.e., Nortase ${ }^{\circledR}$ contains a mixture of lipase, amylase, and protease produced by Rhizopus oryzae and A. oryzae. Very recently, a dramatic increase of false-positive GM-results in patients receiving Nortase ${ }^{\circledR}$ was reported with $75 \%$ of treated individuals testing positive for GM [10]. A whole range of fungi is employed in the industrial production of intravenous drugs, so that GM contamination has been observed repeatedly: examples also include the $\beta$-lactam antibiotics piperacillin and meropenem as well as the antifungal agent caspofungin [37, 38]. All three substances had been administered to the patient as part of the treatment of his infectious complications.

Results of our antifungal susceptibility testing (Table 1) suggested that the isolated T. thermophilus strain was susceptible to echinocandins, voriconazole, and amphotericin B. However, no breakpoints have been defined for Talaromyces species, and testing of thermophilic species like in this case cannot be performed applying standard conditions as suggested by the EUCAST [11]. Furthermore, it is not clear whether the in vitro results reflect the in vivo situation. It is important to note that the Talaromyces IMI occurred under caspofungin treatment.

The current and the previously reported cases of thermophile infections demonstrate that clinicians must be aware of infections due to rare fungal pathogens and that such infections are not limited to hemato-oncological patients [25-30]. Furthermore, laboratories must consider that standard culturing conditions and procedures may fail to identify rare and emerging pathogens with special growth requirements, e.g., prolonged incubation or temperatures other than $37^{\circ} \mathrm{C}$. Antigen testing might be a helpful tool to compensate the limitations of culture-based diagnostics.

Acknowledgements We thank Cornelia Heeg and Christiane Preis for technical support.

Author contributions Conceptualization: KD, IS; methodology: KD, ÖK, JF; formal analysis and investigation: KD, ÖK, JF, IS; writingoriginal draft preparation: KD, IS; writing - review and editing: SS, JW, JA, CS; funding acquisition: not applicable; resources: KD, SS, JW; supervision: KD.

Funding Open Access funding enabled and organized by Projekt DEAL. Not applicable.

Data availability Not applicable.

Code availability Not applicable.

\section{Declarations}

Conflicts of interest For previous studies, KD, JF, and JW report financial support for consumables and supply of technical equipment from 
FUJIFILM Wako Chemical Europe. This funding source was by no means involved in the current report. On behalf of the other authors, the corresponding author states that there is no conflict of interest.

Ethics approval Not applicable.

Consent to participate Not applicable.

Consent for publication Consent of the relatives of the deceased patient to the publication of the case has been obtained.

Open Access This article is licensed under a Creative Commons Attribution 4.0 International License, which permits use, sharing, adaptation, distribution and reproduction in any medium or format, as long as you give appropriate credit to the original author(s) and the source, provide a link to the Creative Commons licence, and indicate if changes were made. The images or other third party material in this article are included in the article's Creative Commons licence, unless indicated otherwise in a credit line to the material. If material is not included in the article's Creative Commons licence and your intended use is not permitted by statutory regulation or exceeds the permitted use, you will need to obtain permission directly from the copyright holder. To view a copy of this licence, visit http://creativecommons.org/licenses/by/4.0/.

\section{References}

1. Brown GD, Denning DW, Gow NA, Levitz SM, Netea MG, White TC (2012) Hidden killers: human fungal infections. Sci Transl Med 4:165rv113. https://doi.org/10.1126/scitranslmed.3004404

2. Hoenigl M, Salmanton-Garcia J, Walsh TJ, Nucci M, Neoh CF, Jenks JD, Lackner M, Sprute R, Al-Hatmi AMS, Bassetti M, Carlesse F, Freiberger T, Koehler P, Lehrnbecher T, Kumar A, Prattes J, Richardson M, Revankar S, Slavin MA, Stemler J, Spiess B, Taj-Aldeen SJ, Warris A, Woo PCY, Young JH, Albus K, Arenz D, Arsic-Arsenijevic V, Bouchara JP, Chinniah TR, Chowdhary A, de Hoog GS, Dimopoulos G, Duarte RF, Hamal P, Meis JF, Mfinanga S, Queiroz-Telles F, Patterson TF, Rahav G, Rogers TR, Rotstein C, Wahyuningsih R, Seidel D, Cornely OA. Global guideline for the diagnosis and management of rare mould infections: an initiative of the European confederation of medical mycology in cooperation with the International society for human and animal mycology and the American society for microbiology. Lancet Infect Dis. 2021. https://doi.org/10.1016/S1473-3099(20) 30784-2.

3. Chowdhary A, Meis JF, Guarro J, de Hoog GS, Kathuria S, Arendrup MC, Arikan-Akdagli S, Akova M, Boekhout T, Caira M, Guinea J, Chakrabarti A, Dannaoui E, van Diepeningen A, Freiberger T, Groll AH, Hope WW, Johnson E, Lackner M, Lagrou K, Lanternier F, Lass-Florl C, Lortholary O, Meletiadis J, Munoz P, Pagano L, Petrikkos G, Richardson MD, Roilides E, Skiada A, Tortorano AM, Ullmann AJ, Verweij PE, Cornely OA, Cuenca-Estrella M, European Society of Clinical M, Infectious Diseases Fungal Infection Study G, European Confederation of Medical M (2014) ESCMID and ECMM joint clinical guidelines for the diagnosis and management of systemic phaeohyphomycosis: diseases caused by black fungi. Clin Microbiol Infect 20:4775. https://doi.org/10.1111/1469-0691.12515

4. Tortorano AM, Richardson M, Roilides E, van Diepeningen A, Caira M, Munoz P, Johnson E, Meletiadis J, Pana ZD, Lackner M, Verweij P, Freiberger T, Cornely OA, Arikan-Akdagli S, Dannaoui E, Groll AH, Lagrou K, Chakrabarti A, Lanternier F, Pagano L, Skiada A, Akova M, Arendrup MC, Boekhout T,
Chowdhary A, Cuenca-Estrella M, Guinea J, Guarro J, de Hoog S, Hope W, Kathuria S, Lortholary O, Meis JF, Ullmann AJ, Petrikkos G, Lass-Florl C, European Society of Clinical M, Infectious Diseases Fungal Infection Study G, European Confederation of Medical M (2014) ESCMID and ECMM joint guidelines on diagnosis and management of hyalohyphomycosis: Fusarium spp., Scedosporium spp. and others. Clin Microbiol Infect 20:27-46. https://doi.org/10.1111/1469-0691.12465

5. Ruhnke M, Behre G, Buchheidt D, Christopeit M, Hamprecht A, Heinz W, Heussel CP, Horger M, Kurzai O, Karthaus M, Loffler J, Maschmeyer G, Penack O, Rieger C, Rickerts V, Ritter J, SchmidtHieber M, Schuelper N, Schwartz S, Ullmann A, Vehreschild JJ, von Lilienfeld-Toal M, Weber T, Wolf HH. Diagnosis of invasive fungal diseases in haematology and oncology: 2018 update of the recommendations of the infectious diseases working party of the German society for hematology and medical oncology (AGIHO). Mycoses. 2018;61:796-813. https://doi.org/10.1111/myc.12838.

6. Lamoth F, Kontoyiannis DP. Therapeutic Challenges of NonAspergillus Invasive Mold Infections in Immunosuppressed Patients. Antimicrob Agents Chemother. 2019;63:e01244-e11219. https://doi.org/10.1128/AAC.01244-19.

7. Cornely OA, Alastruey-Izquierdo A, Arenz D, Chen SCA, Dannaoui E, Hochhegger B, Hoenigl M, Jensen HE, Lagrou K, Lewis RE, Mellinghoff SC, Mer M, Pana ZD, Seidel D, Sheppard DC, Wahba R, Akova M, Alanio A, Al-Hatmi AMS, Arikan-Akdagli S, Badali H, Ben-Ami R, Bonifaz A, Bretagne S, Castagnola E, Chayakulkeeree M, Colombo AL, Corzo-Leon DE, Drgona L, Groll AH, Guinea J, Heussel CP, Ibrahim AS, Kanj SS, Klimko N, Lackner M, Lamoth F, Lanternier F, Lass-Floerl C, Lee DG, Lehrnbecher T, Lmimouni BE, Mares M, Maschmeyer G, Meis JF, Meletiadis J, Morrissey CO, Nucci M, Oladele R, Pagano L, Pasqualotto A, Patel A, Racil Z, Richardson M, Roilides E, Ruhnke M, Seyedmousavi S, Sidharthan N, Singh N, Sinko J, Skiada A, Slavin M, Soman R, Spellberg B, Steinbach W, Tan BH, Ullmann AJ, Vehreschild JJ, Vehreschild M, Walsh TJ, White PL, Wiederhold NP, Zaoutis T, Chakrabarti A, Mucormycosis EMSGGGWG. Global guideline for the diagnosis and management of mucormycosis: an initiative of the European confederation of medical mycology in cooperation with the mycoses study group Education and research consortium. Lancet Infect Dis. 2019;19:e405-21. https://doi.org/10.1016/S1473-3099(19) 30312-3.

8. Richardson M, Page I. Role of Serological Tests in the Diagnosis of Mold Infections. Curr Fungal Infect Rep. 2018;12(3):127-36. https://doi.org/10.1007/s12281-018-0321-1.

9. Wickes BL, Romanelli AM (2020) Diagnostic Mycology: Xtreme Challenges. J Clin Microbiol 58 (4). https://doi.org/10.1128/JCM. 01345-19

10. Schroeder I, Dichtl K, Liebchen U, Wagener J, Irlbeck M, Zoller $\mathrm{M}$, Scharf C. Digestive enzymes of fungal origin as a relevant cause of false positive Aspergillus antigen testing in intensive care unit patients. Infection. 2021;49:241-8. https://doi.org/10.1007/ s15010-020-01506-4.

11. The European Committee on Antimicrobial Susceptibility Testing (2020) Breakpoint tables for interpretation of MICs for antifungal agents, version 10.0. https://www.eucast.org/astoffungi/clinicalbr eakpointsforantifungals/. Accessed 20202020

12. Revankar SG, Patterson JE, Sutton DA, Pullen R, Rinaldi MG. Disseminated phaeohyphomycosis: review of an emerging mycosis. Clin Infect Dis. 2002;34:467-76. https://doi.org/10.1086/ 338636.

13. Bassetti M, Bouza E (2017) Invasive mould infections in the ICU setting: complexities and solutions. J Antimicrob Chemother 72:i39-i47. https://doi.org/10.1093/jac/dkx032

14. Seidel D, Meissner A, Lackner M, Piepenbrock E, SalmantonGarcia J, Stecher M, Mellinghoff S, Hamprecht A, Duran Graeff 
L, Kohler P, Cheng MP, Denis J, Chedotal I, Chander J, Pakstis DL, Los-Arcos I, Slavin M, Montagna MT, Caggiano G, Mares M, Trauth J, Aurbach U, Vehreschild M, Vehreschild JJ, Duarte RF, Herbrecht R, Wisplinghoff H, Cornely OA (2019) Prognostic factors in 264 adults with invasive Scedosporium spp. and Lomentospora prolificans infection reported in the literature and FungiScope((R)). Crit Rev Microbiol 45:1-21. https://doi.org/10. 1080/1040841X.2018.1514366

15. Batista BG, Chaves MA, Reginatto P, Saraiva OJ, Fuentefria AM. Human fusariosis: An emerging infection that is difficult to treat. Rev Soc Bras Med Trop. 2020;53: e20200013. https://doi.org/10. 1590/0037-8682-0013-2020.

16. Garcia-Solache MA, Casadevall A (2010) Global warming will bring new fungal diseases for mammals. mBio 1. https://doi.org/ 10.1128/mBio.00061-10

17. Nature Microbiology Editorial. Stop neglecting fungi. Nat Microbiol. 2017;2:17120. https://doi.org/10.1038/nmicrobiol.2017.120.

18. Limper AH, Adenis A, Le T, Harrison TS. Fungal infections in HIV/AIDS. Lancet Infect Dis. 2017;17:e334-43. https://doi.org/ 10.1016/S1473-3099(17)30303-1.

19. Cao C, Xi L, Chaturvedi V. Talaromycosis (Penicilliosis) due to talaromyces (Penicillium) marneffei: insights into the clinical trends of a major fungal disease 60 years after the discovery of the pathogen. Mycopathologia. 2019;184:709-20. https://doi.org/ 10.1007/s11046-019-00410-2.

20. Samson RA, Yilmaz N, Houbraken J, Spierenburg H, Seifert KA, Peterson SW, Varga J, Frisvad JC. Phylogeny and nomenclature of the genus Talaromyces and taxa accommodated in Penicillium subgenus Biverticillium. Stud Mycol. 2011;70:159-83. https:// doi.org/10.3114/sim.2011.70.04.

21. Donnelly JP, Chen SC, Kauffman CA, Steinbach WJ, Baddley JW, Verweij PE, Clancy CJ, Wingard JR, Lockhart SR, Groll AH, Sorrell TC, Bassetti M, Akan H, Alexander BD, Andes D, Azoulay E, Bialek R, Bradsher RW, Bretagne S, Calandra T, Caliendo AM, Castagnola E, Cruciani M, Cuenca-Estrella M, Decker CF, Desai SR, Fisher B, Harrison T, Heussel CP, Jensen HE, Kibbler CC, Kontoyiannis DP, Kullberg BJ, Lagrou K, Lamoth F, Lehrnbecher T, Loeffler J, Lortholary O, Maertens J, Marchetti O, Marr KA, Masur H, Meis JF, Morrisey CO, Nucci M, Ostrosky-Zeichner L, Pagano L, Patterson TF, Perfect JR, Racil Z, Roilides E, Ruhnke M, Prokop CS, Shoham S, Slavin MA, Stevens DA, Thompson GR, Vazquez JA, Viscoli C, Walsh TJ, Warris A, Wheat LJ, White PL, Zaoutis TE, Pappas PG. Revision and update of the consensus definitions of invasive fungal disease from the European organization for research and treatment of cancer and the mycoses study group education and research consortium. Clin Infect Dis. 2019. https://doi.org/10.1093/cid/ciz1008.

22. Maheshwari R, Bharadwaj G, Bhat MK. Thermophilic fungi: their physiology and enzymes. Microbiol Mol Biol Rev. 2000;64:46188. https://doi.org/10.1128/MMBR.64.3.461-488.2000.

23. Zhang JM, Wang HH, Liu X, Hu CH, Zou Y. Heterologous and Engineered Biosynthesis of Nematocidal Polyketide-Nonribosomal Peptide Hybrid Macrolactone from Extreme Thermophilic Fungi. J Am Chem Soc. 2020;142:1957-65. https://doi.org/10. 1021/jacs.9b11410.

24. Houbraken J, de Vries RP, Samson RA. Modern taxonomy of biotechnologically important Aspergillus and Penicillium species. Adv Appl Microbiol. 2014;86:199-249. https://doi.org/10.1016/ B978-0-12-800262-9.00004-4.

25. Morio F, Fraissinet F, Gastinne T, Le Pape P, Delaunay J, Sigler L, Gibas CF, Miegeville M. Invasive Myceliophthora thermophila infection mimicking invasive aspergillosis in a neutropenic patient: a new cause of cross-reactivity with the Aspergillus galactomannan serum antigen assay. Med Mycol. 2011;49:883-6. https://doi.org/10.3109/13693786.2011.584218.

26. Destino L, Sutton DA, Helon AL, Havens PL, Thometz JG, Willoughby RE Jr, Chusid MJ. Severe osteomyelitis caused by Myceliophthora thermophila after a pitchfork injury. Ann Clin Microbiol Antimicrob. 2006;5:21. https://doi.org/10.1186/ 1476-0711-5-21.

27. Farina C, Gamba A, Tambini R, Beguin H, Trouillet JL. Fatal aortic Myceliophthora thermophila infection in a patient affected by cystic medial necrosis. Med Mycol. 1998;36:113-8.

28. Mares M, Moroti-Constantinescu VR, Voroneanu L, Doroftei F, Covic A, Mederle OA. Invasive pulmonary infection due to Thermoascus crustaceus in a kidney transplant recipient. Infect Drug Resist. 2019;12:1929-34. https://doi.org/10.2147/IDR.S209164.

29. Alvarez E, Castillo A, Iturrieta I. Fungal peritonitis by Thermoascus crustaceus in a peritoneal dialysis patient from Chile. Rev Iberoam Micol. 2017;34:225-8. https://doi.org/10.1016/j.riam. 2017.01.004.

30. Oz Y, Kiraz N, Ozkurt S, Soydan M. Colonization of peritoneal catheter with a thermophilic fungus, Thermoascus crustaceus: a case report. Med Mycol. 2010;48:1105-7. https://doi.org/10.3109/ 13693781003793838.

31. Ahamefula Osibe D, Lei S, Wang B, Jin C, Fang W. Cell wall polysaccharides from pathogenic fungi for diagnosis of fungal infectious disease. Mycoses. 2020;63:644-52. https://doi.org/10. 1111/myc.13101.

32. Dichtl K, Forster J, Ormanns S, Horns H, Suerbaum S, Seybold U, Wagener J (2020) Comparison of beta-D-Glucan and Galactomannan in Serum for Detection of Invasive Aspergillosis: Retrospective Analysis with Focus on Early Diagnosis. J Fungi (Basel) 6 (4). https://doi.org/10.3390/jof6040253

33. Furfaro E, Giacobbe DR, Del Bono V, Signori A, Guolo F, Minetto P, Clavio M, Ballerini F, Gobbi M, Viscoli C, Mikulska M. Performance of serum $(1,3)$-ss-d-glucan screening for the diagnosis of invasive aspergillosis in neutropenic patients with haematological malignancies. Mycoses. 2018;61:650-5. https:// doi.org/10.1111/myc.12787.

34. Worasilchai N, Leelahavanichkul A, Kanjanabuch T, Thongbor N, Lorvinitnun P, Sukhontasing K, Finkelman M, Chindamporn A. (1->3)-beta-D-glucan and galactomannan testing for the diagnosis of fungal peritonitis in peritoneal dialysis patients, a pilot study. Med Mycol. 2015;53:338-46. https://doi.org/10.1093/mmy/ myv007.

35. Dichtl K, Wagener J, Tschop J, Ney L. Analysis of peritoneal galactomannan for the diagnosis of Aspergillus peritonitis. Infection. 2016;44:683-6. https://doi.org/10.1007/s15010-016-0902-2.

36. Leelahavanichkul A, Pongpirul K, Thongbor N, Worasilchai $\mathrm{N}$, Petphuak K, Thongsawang B, Towannang P, Lorvinitnun P, Sukhontasing K, Katavetin P, Praditpornsilpa K, Eiam-Ong S, Chindamporn A, Kanjanabuch T. (1->3)-beta-d-glucan and galactomannan for differentiating chemical "black particles" and fungal particles inside peritoneal dialysis tubing. Perit Dial Int. 2016;36:402-9. https://doi.org/10.3747/pdi.2014.00235.

37. Steinmann J, Buer J, Rath PM. Caspofungin: cross-reactivity in the Aspergillus antigen assay. J Clin Microbiol. 2010;48:2313. https://doi.org/10.1128/JCM.00118-10.

38. Ansorg R, van den Boom R, Rath PM. Detection of Aspergillus galactomannan antigen in foods and antibiotics. Mycoses. 1997;40:353-7. https://doi.org/10.1111/j.1439-0507.1997.tb002 49.x. 